\title{
Determination of radial pressure distribution on the wall of the press channel of a novel biomass single die pelletiser
}

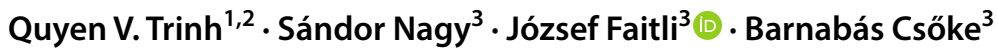

Received: 19 November 2019 / Published online: 17 August 2020

(c) The Author(s) 2020

\begin{abstract}
Pressure is an important process parameter that greatly influences the density of biomass pellets. The positive number of Poisson's ratio of biomasses makes pelletising possible in ring die and flat die types of pelletisers, because as a consequence of the longitudinal direction of load, the material strains into the radial direction. The radial strain is obstructed by the channel wall and therefore radial pressure and wall friction occur, which supports (backs) the compression of the further sequentially loaded biomass. A novel test device consisting of a single pelletising unit and a novel sensor, a back pressure measurement disc was developed and calibrated. Pelletising experiments were carried out with a flat die pelletising machine and with the single pelletiser unit with ground post agglomerated (GPA)-spelt chaff (chaff of triticum spelta) samples. The body density and radial pressure values in different pelletising unit segments were measured. The equations introduced for dimensionless relative density and for radial pressure as a function of the relative position equations fit the measured data well.
\end{abstract}

\section{Abbreviations \\ GPA Spelt chaff: ground post agglomerated (GPA)- spelt chaff (chaff of triticum spelta) \\ POM Polyoxymethylene \\ BPMD Back pressure measurement disc}

\section{Introduction}

The use of biomass as fuel is a good option for domestic heating systems and power plants to reduce net $\mathrm{CO}_{2}$ emissions. Pelletising is currently one of the most frequently used methods for producing agglomerates, using either a ring die or a flat die pelletiser. This process can increase bulk density, reduces storage and transportation costs and makes handling of the biomass easier. Different types of biomasses from various sources can act as raw materials for fuel pellet production. The composition and structural properties of these

József Faitli

ejtfaitj@uni-miskolc.hu

1 Institute of Institute of Theoretical and Applied Research, Duy Tan University, Hanoi 100000, Vietnam

2 Faculty of Environmental and Chemical Engineering, Duy Tan University, Dang Nang 550000, Vietnam

3 Institute of Raw Material Preparation and Environmental Processing, University of Miskolc, Miskolc-Egyetemváros 3515, Hungary materials are diverse. Different types of biomass require different processing conditions, including press channel length, moisture content, particle size and temperature. Nowadays, process optimization is still mainly based on expensive and time-consuming "trial and error" experiments and personal experience (Holm et al. 2011). The globally installed pellet production capacity for 2011 was estimated to be about 30 million tonnes. All studies indicate a growth forecast for both the European and North American pellet markets. The Finnish Pöyry Industry consulting company has predicted growth in global pellet production capacity to 46 million tonnes by 2020 (Pöyry 2011) and a figure of 65 million tonnes has been forecast by 2025 (Strauss 2017).

The pressure applied to the biomass during pelletising and briquetting has a significant impact on product density and durability, as well as on the energy consumption of the process. Therefore, this process parameter had been subject of many studies (Adapa et al. 2009; Carone et al. 2011; Gilbert et al. 2009; Kaliyan and Morey 2009; Mani et al. 2006; Odogherty and Wheeler 1984; Smith et al. 1977; Stelte et al. 2011). In all the studies, there is a very clear agreement and conclusion that pellet and briquette density increase with an increase in pressure. The applied maximum pressures ranged from $50 \mathrm{MPa}$ (Odogherty and Wheeler 1984) to $600 \mathrm{MPa}$ (Stelte et al. 2011). Pressures typically used in most of the studies were above $50 \mathrm{MPa}$ in the case of open form pelletising (Adapa et al. 2009; Mani et al. 2006; Stelte et al. 2011). Holm et al. (2007) measured the back pressure needed to press pellets 
of different lengths out of the press channel. It was found that the pelletising pressure increases exponentially as a function of the pellet length. Experiments also showed that the back pressure depends on biomass species for all tested pellet lengths. Stelte et al. (2011) also showed that the pelletising pressure increases exponentially with the pellet length. Increasing pelletising pressure results in increased pellet density.

Holm et al. (2006) developed a theoretical model to explain this exponential pressure-pellet length relationship. This paper is a fundamental work because it gives a theoretical background to why pelletising is possible in a press channel. According to their model, the fundament of flat die or ring die pelletising is the different strain ratio in the longitudinal and radial directions of materials in the press channel. Figure 1 illustrates the theoretical model of Holm et al. (2006).

The height of the elementary "disc shaped" segment is dx. If this element is loaded by pressure in a longitudinal direction $\left(p_{\mathrm{L}}\right)$ it compresses. The question is what happens with the segment in the radial direction. On the one hand, the Poisson ratio $\left(\nu_{\mathrm{RL}}\right)$ of materials is the ratio between the radial and longitudinal strains under compression and $\nu_{\mathrm{LR}}$ is the ratio between the longitudinal and radial strains. If a material's Poisson's ratio was higher than 0 , this material would extend (positive strain) in radial direction. The wall of the press channel is considered to be rigid; therefore, no strain is possible in the radial direction, instead this results in a pressure normal to the channel wall $\left(p_{R}\right)$. This wall friction supports ("backs" according to the vocabulary of Holms et al.) the material in the channel, therefore further compression is possible. On the other hand, stress-strain relations of materials both in longitudinal $\left(\mathrm{E}_{\mathrm{L}}-\right.$ longitudinal elasticity modulus) and radial $\left(\mathrm{E}_{\mathrm{R}}\right.$-radial elasticity modulus) directions also have to be taken into account.

$\frac{p_{L}}{p_{R}}=\frac{E_{L}}{E_{R}} \cdot v_{R L}=v_{L R}$

Holm et al. (2006) first wrote and solved the differential equation when only linear elasticity was assumed. This model assumes that after the load the material gains back

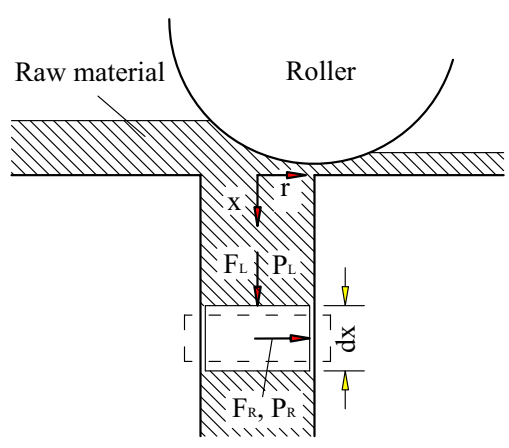

Fig. 1 Elementary segment under pressure in the press channel (springs back to) its original form, but evidently this is not the case of real pelletising, because pellets do not fall out freely from the channel. Therefore, they introduced the "prestressing pressure" $\left(\mathrm{p}_{\mathrm{No}}\right)$ term and wrote and solved the improved differential equation for modelling plastic deformation too. The developed pellet lengths (compression ratio)-longitudinal pressure relation is as follows:

$p_{x}=\frac{p_{N o}}{v_{L R}}\left(e^{2 \cdot \mu \cdot v_{L R} \cdot \frac{x}{r}-1}\right)$

where $\mathrm{p}_{\mathrm{x}}$ is pelletizing pressure, $p_{N o}$ is prestressing pressure, $\mu$ is sliding friction coefficient, $x$ is the direction of transverse deformation, and $r$ is radius of press channel. Equation 2 has been experimentally confirmed by many authors (Holm et al. 2007; Stelte et al. 2011).

The effect of raw material moisture content on the pelletising properties and product quality has also been the subject of several studies (Andreiko and Grochowicz 2007; Arshadi et al. 2008; Carone et al. 2011; Filbakk et al. 2011; Kaliyan and Morey 2009; Mani et al. 2006; Nielsen et al. 2009b, 2010; Odogherty and Wheeler 1984; Rhen et al. 2005; Ryu et al. 2008; Serrano et al. 2011; Smith et al. 1977; Stelte et al. 2011). In these studies, biomasses were pelletized at different levels of moisture content, and its impact on the pellet quality (durability or compression stability) was analysed. In general, the optimum moisture content for wood species was found to be between 5 and $10 \mathrm{wt} \%$, while slightly higher for agricultural grasses at 10-20 wt $\%$.

Studies with a variety of materials have found that an increase in mechanical load on the pellets results in an increase in temperature. This has been reported for spruce (Rhen et al. 2005), corn stover (Kaliyan and Morey 2009), switch grass (Gilbert et al. 2009), pine (Nielsen et al. 2009a), olive (Carone et al. 2011), beech (Nielsen et al. 2009a), and wheat straw (Stelte et al. 2012). Furthermore, it was reported that an increase in temperature reduces the friction in the press channel of the pelletiser (Stelte et al. 2011) and lowers the energy requirement for different components of the pelletising process (Nielsen et al. 2009a).

Trinh and Nagy (2016) suggested a method that allows pellet producers to estimate pelletising behaviours of raw materials by conducting a few tests in a single pelletiser unit. This enables rapid estimation of key process parameters such as optimal press channel length, moisture content, applied pressure, temperature, particle size and speed of piston.

During continuous pelletisation of biomasses, a back (support) pressure is needed to initiate the process. The back pressure is created by the build-up of material in the press channel, which sets the requirement for a pressure (pre-stressing pressure) to overcome the friction within the channels. The initial pelletisation pressure depends on the die's physical dimensions (die hole diameter, die length), its 
frictional coefficient and pre-stressing pressure (Holm et al. 2006; Tumuluru et al. 2010). Although many researchers have studied the effect of compaction pressure on the pelletising process, only few of them, such as Holm et al. 2007 and Stelte et al. 2011, discuss the back pressure in the press channel.

Recent studies discussed the temperature effect of die pelletisation processes, for example Yanming et al. (2018) confirmed that the optimum moisture content is around $10 \mathrm{wt} \%$ and a suitable die temperature is $160-200^{\circ} \mathrm{C}$ when producing bamboo pellets. Lisowski et al. (2019) reported the good strength of the pellets of walnut shells with densities higher than $820 \mathrm{~kg} / \mathrm{m}^{3}$ were obtained at the moisture content of $18.3 \mathrm{wt} \%$ and temperature of $93{ }^{\circ} \mathrm{C}$.

Hence, the major objective of the present research was the development of a new pressure distribution measurement method for fuel biomass production. A single pelletiser unit has been developed with which the back pressure gradient in the direction of the applied force can be measured at three different positions along the active part length of the die channel. The normal stress-perpendicular to the die surface-was measured by a newly designed load cell element. The measured pressure distribution data in the active part of the press channel makes the empirical pelletizing optimization more precise and contributes to a better understanding of the agglomeration process inside the die.

\section{Materials and methods}

\subsection{Materials}

Biomass pellets made by industrial and household spelt chaff (triticum spelta) are generally used for energy generation; therefore, this material stream is a good model material for the experiments. A sample was taken from Szendrő, Hungary (Natur Gold Farms Ltd.). The total sample was dried and then ground using a cutting mill (Retsch SM2000) in one step (with $2 \mathrm{~mm}$ opening size screen). Moisture content and bulk density of the cut spelt chaff biomass sample (particle size $<1.6 \mathrm{~mm}$ ) was determined; the results were $5.3 \mathrm{wt} \%$ and $193 \mathrm{~kg} / \mathrm{m}^{3}$, respectively. This sample state is called "raw material" spelt chaff and it can be seen in Fig. 2(left). Based on the microscope photos, it can be observed that the raw material spelt chaff is quite a homogeneous material.

A so called "ground post-agglomerated spelt chaff" (GPA-spelt chaff) subsample was prepared for subsequent agglomeration experiments. GPA-spelt chaff was made by agglomerating and then cutting again the raw material spelt chaff biomass subsample. At this second cutting, a $1 \mathrm{~mm}$ opening size sieve was used. Moisture content and bulk density of the GPA-spelt chaff biomass sample (particle size $<1 \mathrm{~mm}$ ) was also measured; results were $10 \mathrm{wt} \%$ and $354 \mathrm{~kg} / \mathrm{m}^{3}$ respectively. The moisture content of GPA-spelt chaff was later adjusted to be $20 \mathrm{wt} \%$ by adding extra water to the sample. The prepared ground post-agglomerated spelt chaff (GPA) can be seen in Fig. 2(right). Figure 3 shows the particle size distributions of spelt chaff raw material and ground post-agglomerated spelt chaff samples.

\subsection{Equipment and methods used for research}

\subsubsection{Flat die pelletiser}

The applied flat die pelletiser system (Fig. 4) contains a flat die press, mixing container, conditioning screw and a steam generator (Theobald TJ-Extra II, $19 \mathrm{~kg} / \mathrm{h}$ steam capacity). The nominal capacity of this pelletiser system is $50-100 \mathrm{~kg} / \mathrm{h}$ depending on the type of the material fed. For the described experiments, it was $60 \mathrm{~kg} / \mathrm{h}$. The outer diameter of the flat die is $200 \mathrm{~mm}$, the length of the holes is $28 \mathrm{~mm}$ and their inner diameter is $8 \mathrm{~mm}$. The geometrical form of a die hole is shown on the right side of Fig. 4.

\subsubsection{Development of the single pelletiser unit}

The newly designed press channel, called the single pelletiser unit, is shown in Fig. 5. The single pelletiser unit is mounted on a hydraulic piston press (Fig. 6). The length of the active part is $55 \mathrm{~mm}$ and it includes three segments made
Fig. 2 Spelt chaff raw material with $x<1.6 \mathrm{~mm}$ (left); Ground post-agglomerated spelt chaff with $x<1 \mathrm{~mm}$ (right) (Optical microscope: Zeiss AXIO Imager.M2m)
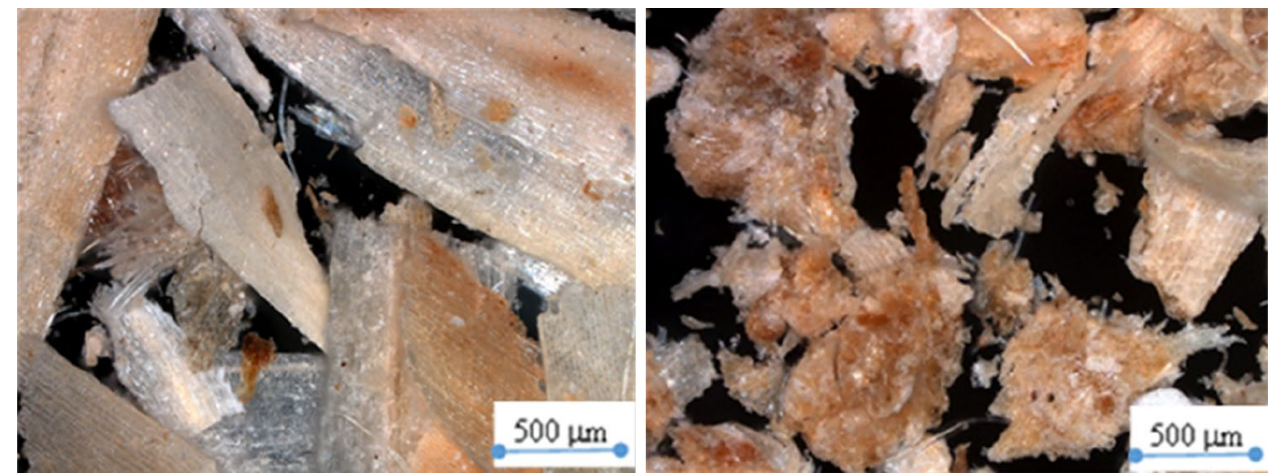


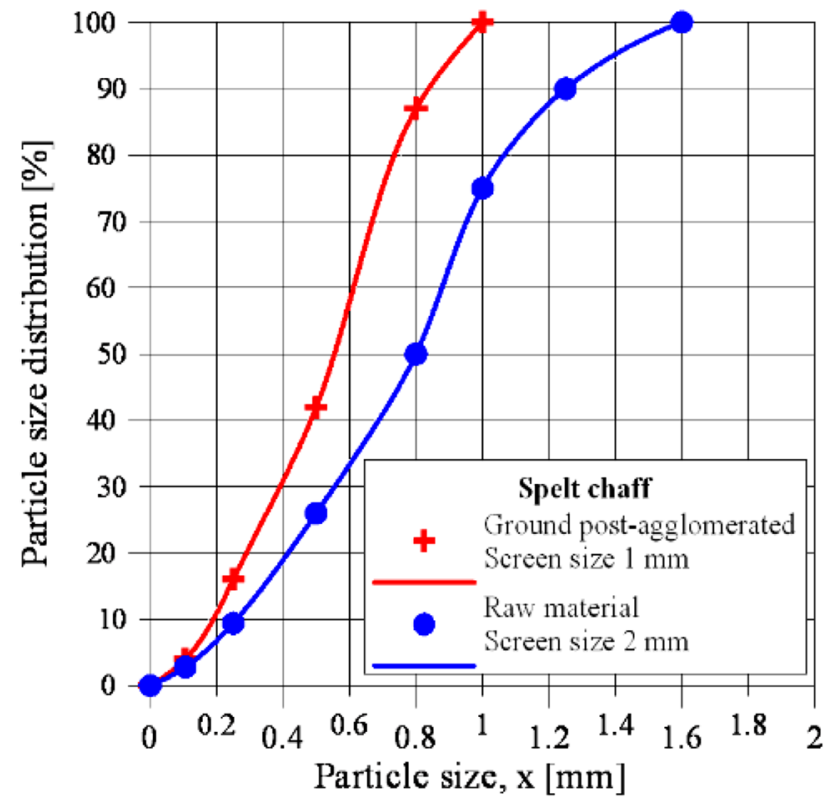

Fig. 3 Particle size distributions of spelt chaff and GPA-spelt chaff samples

of carbon steel and one segment made of polyoxymethylene (POM). The length of each segment is $13.75 \mathrm{~mm}$ and the diameter of the hole is $8 \mathrm{~mm}$. A pressure transducer is built in (type: PU5402-100 bar made by Ifm Electronics) to measure back pressure. This pressure transducer is a deadspace type device; therefore, a fill in liquid was necessary to transfer pressure from the pelletiser unit membrane into the membrane of the pressure transducer. A mixture of glycerine and alcohol was used. The back pressure distribution was measured in four discrete steps. For these measurements, pelletising under identical parameters was repeated three times, when the load cell made of POM (called the back pressure measurement disc, BPMD) was positioned into the four discrete positions. To determine measurement accuracy a statistical analysis was carried out. Sample average and sample corrected standard deviation values were calculated for every measured pellet density $(\rho)$, radial back pressure $\left(\mathrm{p}_{\mathrm{R}}\right)$ and number (n) of sequentially fed raw material portions (layers) values. With the help of the Student distribution, a confidence interval for the population mean around the sample average with $95 \%$ confidence level was calculated. This confidence interval is called margin of error. The calculated margin of error values-converted into percentage units - are $\left[\rho_{\text {average }}\right] \pm 1.8 \%$ for pellet density, $\left[\mathrm{p}_{\text {Raverage }}\right] \pm 0.7 \%$ for radial back pressure and $\left[\mathrm{n}_{\text {average }}\right] \pm 2 \%$ for number of sequentially fed raw material layers values. Only the measured average values of three parallel tests are shown throughout the paper. A piston (diameter: $8 \mathrm{~mm}$, active length: $15 \mathrm{~mm}$ limited by a $30 \mathrm{~mm}$ diameter cylinder) can force the raw material into the pelletising chamber.

\subsubsection{Calibration of the equipment}

Proper calibration of the back pressure measuring system was extremely important. The nominal measuring range and output voltage of the applied PU5402 pressure transducer is $0-100$ bar and $0-10 \mathrm{~V}$, respectively. The pressure transducer itself was re-calibrated using compressed air for loading the transducer with a reference pressure. The reference air pressure loading the transducer was measured by another pressure measuring device, namely a Hottinger Digibar pressure transducer was used. Reference pressures from 0.08 to 6 bar
Fig. 4 Flat die pelletiser (left); hold length (right)

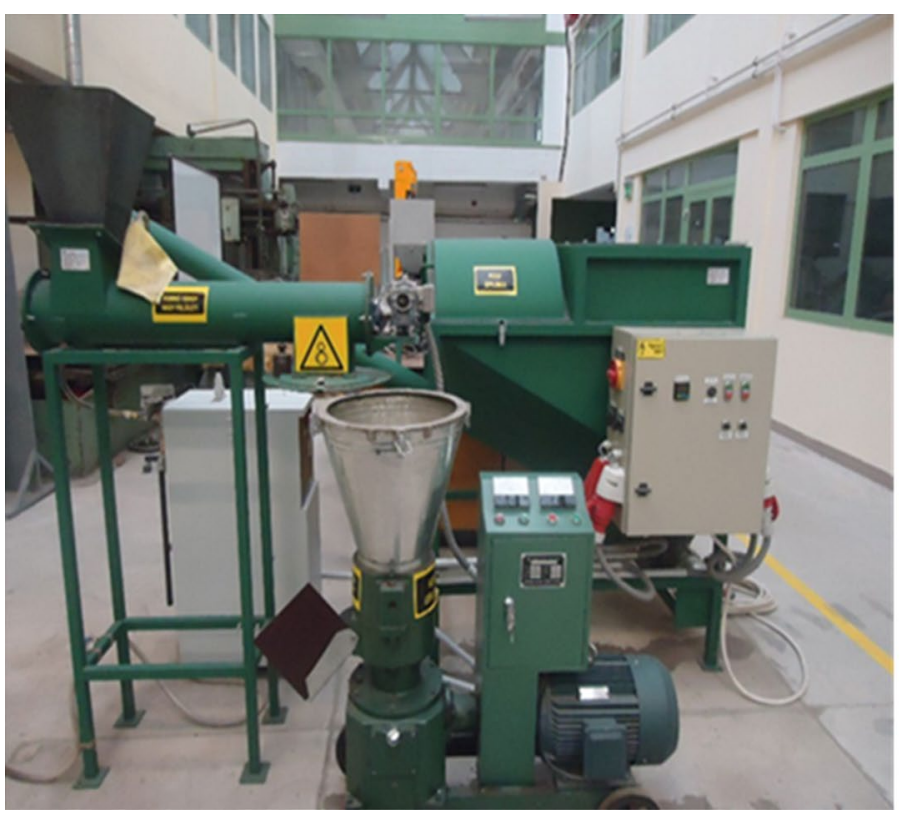



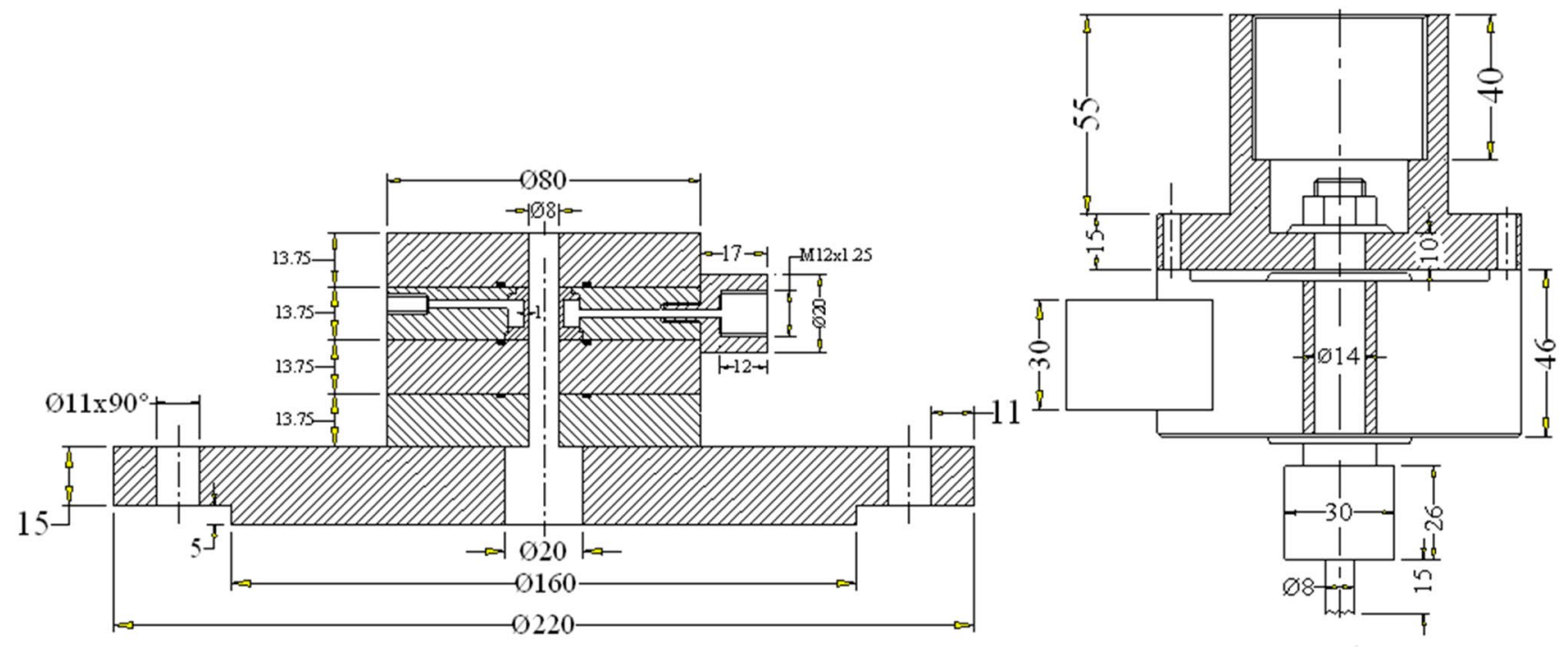

Fig. 5 New design press channel and piston of single pelletiser unit

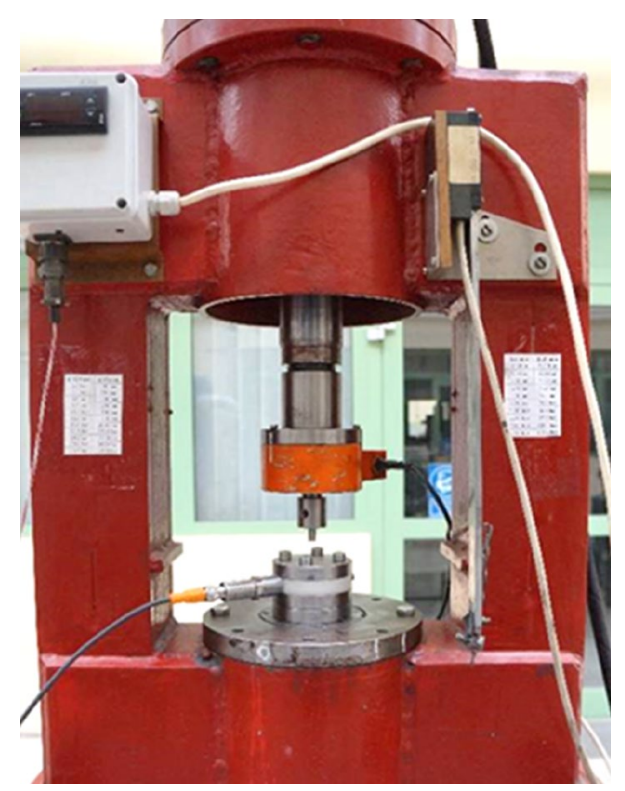

in step increments of 0.3 bar were set in the air supply tank (type EN286-1) for calibration.

A hydraulic pressure calibration system was developed for the calibration of the POM load cell for measuring back pressure. There were two major issues that had to be solved. One challenge was to identify a suitable liquid for filling in the load cell without air bubbles, from a substance that does not destroy the POM material and the used adhesive. The second challenge was the loading of the pelletising channel wall by a reference pressure. Figure 7 shows detailed sizes of the developed load cell (BPMD). There are two holes in it, marked A and B. Prior to the actual calibration, the cell was filled by a liquid (75 wt $\%$ glycerine and $25 \mathrm{wt} \%$ alcohol) through hole B when hole A was open. When no more air came through hole A, hole A was closed. The prepared liquid was poured into the hole of the pressure transducer and then screw $\mathrm{B}$ was connected to the pressure transducer when hole A was open. The screw in hole A was adjusted for the liquid pressure of 3 bar as shown in Figs. 7 and 8(left).

Fig. 6 Hydraulic piston press with the single pelletiser unit

Fig. 7 Design of back pressure measurement disc (BPMD)

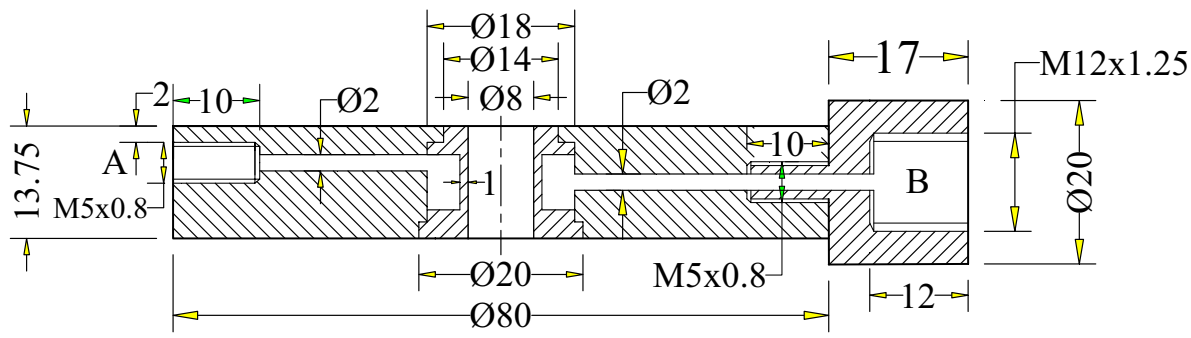


The back-pressure measurement in the pelletising chamber was calibrated using the developed hydraulic pressure calibration system, see Fig. 8(right). The calibration was carried out by adjusting the screw on the top of the system to increase liquid pressure. It was adjusted from 0 to $25 \mathrm{bar}$ in steps of 1 bar and then the reference pressure and voltage output of the digital voltage meter were read, and it was repeated for all test points. Figure 9 shows the results of calibration using the developed hydraulic pressure calibration system.

The BPMD test disc and especially the used pressure transducer had been calibrated only at $20^{\circ} \mathrm{C}$ normal room temperature; however, tests were carried out at $60^{\circ} \mathrm{C}$ too. The temperature dependency of the density of the filling liquid (75 wt \% glycerine and $25 \mathrm{wt} \%$ alcohol) affects pressure measurements. The relative density change of $60{ }^{\circ} \mathrm{C}$ temperature glycerine compared to the $20^{\circ} \mathrm{C}$ one is $-1.9 \%$. However, the actual temperature of the filling liquid in the cell during a $60{ }^{\circ} \mathrm{C}$ test cannot be estimated, because only the die was heated and the massive head of the pressure transducer was not. Margin of error of $20^{\circ} \mathrm{C}$ pressure measurements was $\left[p_{\text {Raverage }}\right] \pm 0.7 \%$. It is simply estimated here that margin of error of $60{ }^{\circ} \mathrm{C}$ pressure measurements was about $\left[p_{\text {Raverage }}\right] \pm 2 \%$.

\subsubsection{Developed experimental procedure}

The developed single pelletiser unit was used for tests in different configurations with and without the developed load cell. Prior to a back pressure measurement pelletising test, proper filling of the channel is necessary. For this purpose, the following experimental procedure was developed to model the so-called sequential load type of industrial flat die pelletisers (Fig. 1). During a revolution of the flat die, a roll presses only a small raw material portion into the channels. Therefore, the feed is sequential. Prior to each pelletising test, $0.3 \mathrm{~g}$ of prepared GPA-spelt chaff $(<1 \mathrm{~mm}$ and $20 \mathrm{wt} \%$ moisture content) was fed into the channel. Before the load of the first raw material portion, a soft material, namely a piece of sponge, was inserted into the pelletising channel to supply the necessary back pressure for pelletisation initialisation. The $15 \mathrm{~mm}$ length piston was pressed

Fig. 8 Set up pressure value in the back -pressure measurement load cell (left) and hydraulic pressure calibration system (right)
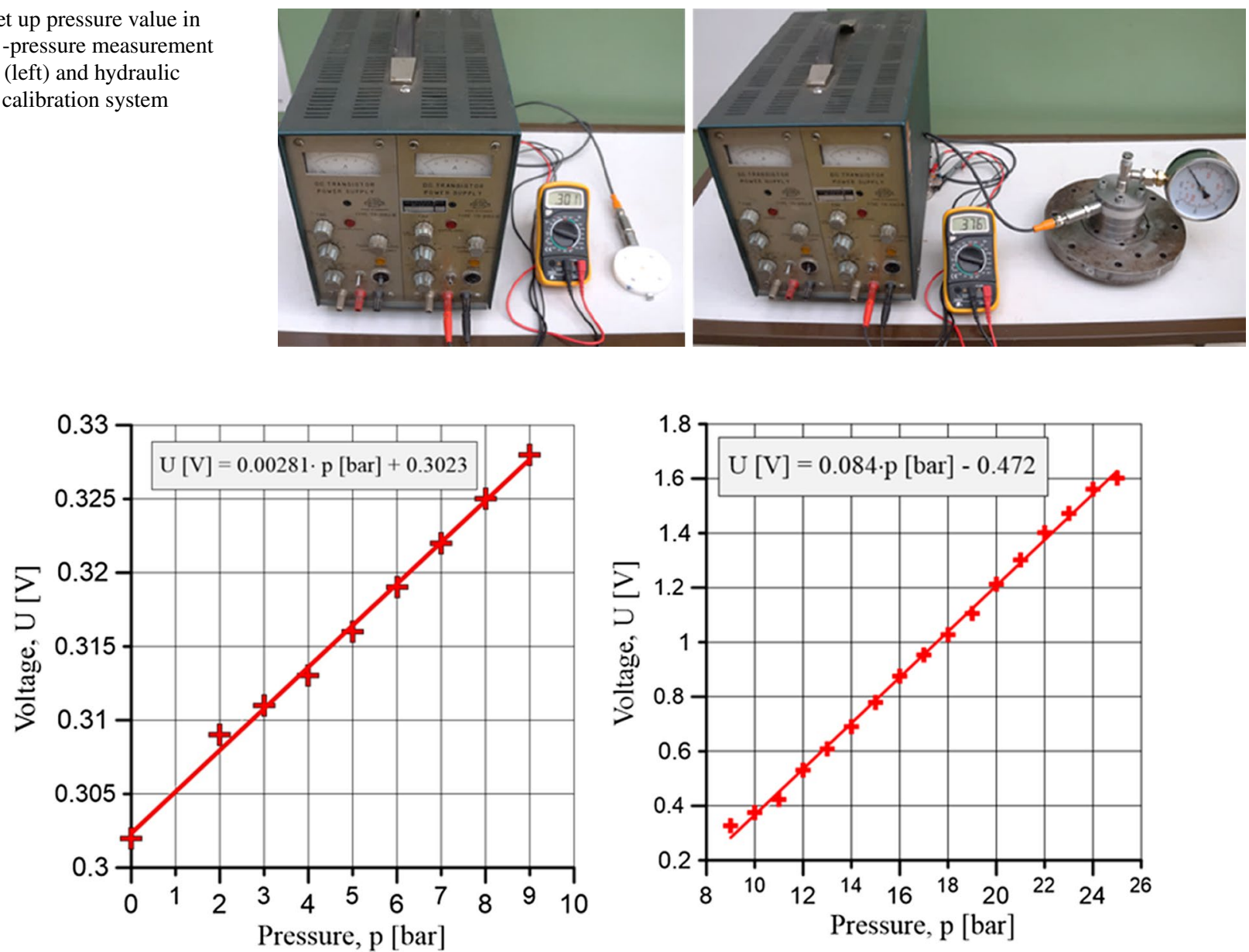

Fig. 9 Calibration results for back pressure in the chamber; (left) 0-9 bar; (right) 9-25 bar 
into the channel completely and then lifted. Some more material was added to the channel and the piston moved down again. This was repeated until $10 \mathrm{~g}$ raw material had been fed into the channel and until the process of agglomeration,-namely the downward motion of the piston-was stopped. During sequential feeding, a careful test protocol and cleaning had to be applied to avoid some remaining materials on top of the unit segments, to avoid unwanted compression of spilled materials between piston rim and top unit segment. The number of loaded layers is marked by $n$. At this point, when the piston tip was stopped and it was at about $x=0 \mathrm{~mm}$ (Fig. 10), the pressed material in the channel supported (backed) the piston. The starting point of the $\mathrm{x}$ longitudinal axis is set to be zero in the height between pelletiser unit segments 1 and 2, as shown in Fig. 10. The oil pressure in the hydraulic cylinder of the piston press was limited to 21.5 bar by the pressure relief valve for all the tests. The 21.5 bar oil pressure in the hydraulic cylinder corresponds to 3500 bar pressure on the surface of the $8 \mathrm{~mm}$ diameter piston. The speed of the piston was set to $6 \mathrm{~mm} / \mathrm{s}$ for all the tests.

Pelletising experiments with a given material were carried out at all of the following single pelletiser unit configurations. At $20^{\circ} \mathrm{C}$ temperature, pelletising tests were carried out with four steel segments without membrane, with three steel segments and one POM segment without membrane and with three steel segments with the BPMD segment membrane. Wall friction coefficients, elasticity modulus and Poisson's ratios of POM and steel are different; therefore, these combinations were tested. At $20{ }^{\circ} \mathrm{C}$ and $60{ }^{\circ} \mathrm{C}$ temperatures, the position of the BPMD load cell segment was also tested, namely repeated tests were carried out when the cell was positioned on pelletiser segments no. 2 , on no. 3 or on no. 4.

After agglomeration ceased, namely when the longitudinal back pressure of the produced pellet supported the piston, the pellet was removed from the unit. The quality of pellets can be described easily by their body density. The

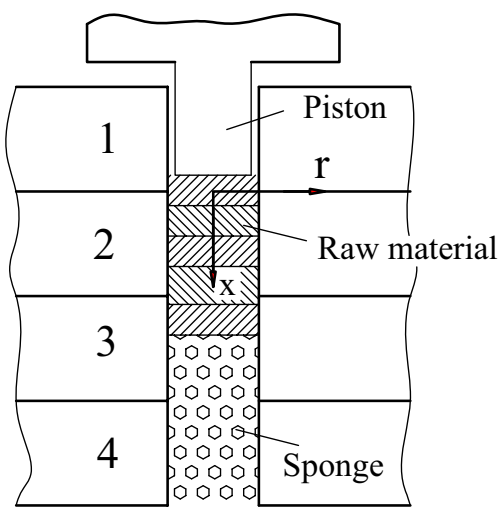

Fig. 10 Sequential feed of the single pelletiser unit removed pellet was cut into three pieces according to the three active pelletiser unit segments (Fig. 10), therefore; the pellet density distribution in the channel was also measured. This research focused on the pressure distribution rather than process optimisation, therefore other pellet durability and strength tests such as the drop down test had not been carried out. The spring back ratio of the removed pellets was neglected. Diameters and heights of pellet segments were measured by a Vernier caliper. The mass was measured and density was calculated for each pellet segment.

Wall friction coefficients were measured by a Jenike shear tester (Fig. 11) only at room temperature. The friction coefficient between GPA-spelt chaff and carbon steel $\left(\mu_{\text {GPA-st }}=0.299\right)$ and between GPA-spelt chaff and POM $\left(\mu_{\mathrm{GPA}-\mathrm{POM}}=0.386\right)$ was measured.

\section{Results and discussion}

The piston was stopped, namely the maximal set oil pressure was reached, after a maximum of 16 subsequent raw material layers in the case of all active segments made from carbon steel and a maximum of 34 layers in the case of two small segments made from carbon steel and one segment made from POM (without membrane). The first reason for the difference in the number of layers is that the material does not flow continuously, so it has time to stick to the wall of the active part, which may impede material movement. The temperature of the active part of the model single pelletiser unit is considerably lower than the operational temperature of flat die pelletisers $\left(100{ }^{\circ} \mathrm{C}\right)$. The second reason for that can probably be explained by the Poisson ratio (Zhu et al. 2017), which is higher for POM (0.35) than for carbon steel (0.27-0.3) (Gercek 2007; Howatson et al. 1991). It is not assumed here that the elastic deformation of the wall of the pelletiser unit is significant, but different pelletising

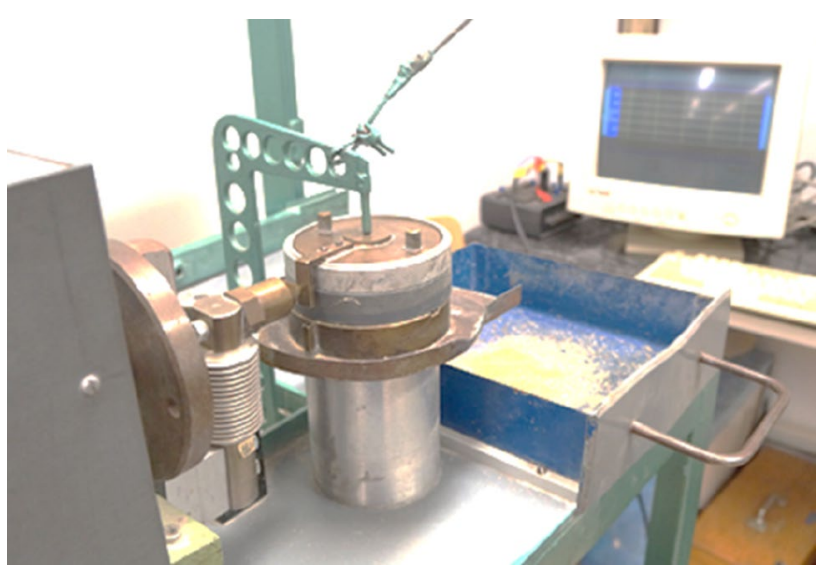

Fig. 11 Jenike shear tester 
behaviour was detected among the carbon steel, POM and the load cell (BPMD) pelletiser unit segment wall materials. The wall friction coefficient between GPA-spelt chaff and POM (0.386) is higher than that between GPA-spelt chaff and carbon steel (0.299). This is a remarkable difference. The position of the BPMD load cell influenced the number (n) of sequentially fed raw material portions (layers). At the same temperature and moisture content, when BPMD was positioned in the $2^{\text {nd }}$ pelletiser unit segment, the number of layers was maximal $\left(\mathrm{n}_{\max }\right)$. The reason for this observed phenomenon might be the higher elastic deformation of the POM wall compared to carbon steel, meaning the material could flow downward more easily in the active part. Table 1 shows the measured number of layers and radial back pressure $\left(p_{R}-\right.$ pressure perpendicular to the press channel wall) results as a function of the BPMD position and temperature.

In the case of the $20^{\circ} \mathrm{C}$ temperature tests, after the feed of ten raw material layers ( $0.3 \mathrm{~g}$ each) and when the BPMD was positioned in the 3 rd pelletiser unit segment, the measured radial pressure in the cell was $2.7 \mathrm{bar}$. After the feed of 29 layers, the piston was stopped, and the measured radial pressure was 9.9 bar in the 3rd segment. Data in Table 1 should be interpreted accordingly. When no more compression was possible, because the pre-set maximal oil pressure in the hydraulic cylinder had been reached, pelletising was stopped, the pellet was removed and cut, and the body density of each segment was measured as described earlier. Figure 12 shows some pellets made by the single pelletiser unit at $60^{\circ} \mathrm{C}$ and with $20 \mathrm{wt} \%$ moisture content as an example.

The BPMD load cell was positioned into pelletiser segments no. 2, 3 and 4 at a time. The body density of a pellet segment slightly depends on the position of the BPMD device. If the BPMD was in segment no. 2, the body density of pellet segment no. 3 was $971 \mathrm{~kg} / \mathrm{m}^{3}$, while when the BPMD was in segment no. 4 , the pellet segment density of the same position decreased to $856 \mathrm{~kg} / \mathrm{m}^{3}$. Data in Table 2 should be interpreted accordingly. Possible reasons for this observed phenomenon were described above. Table 2 also shows that the applied higher pelletising temperature resulted in higher body pellet segments densities for the same moisture content raw materials ( $20 \mathrm{wt} \%)$. The weight of a produced pellet segment in the active part was typically $2.5 \mathrm{~g}$.

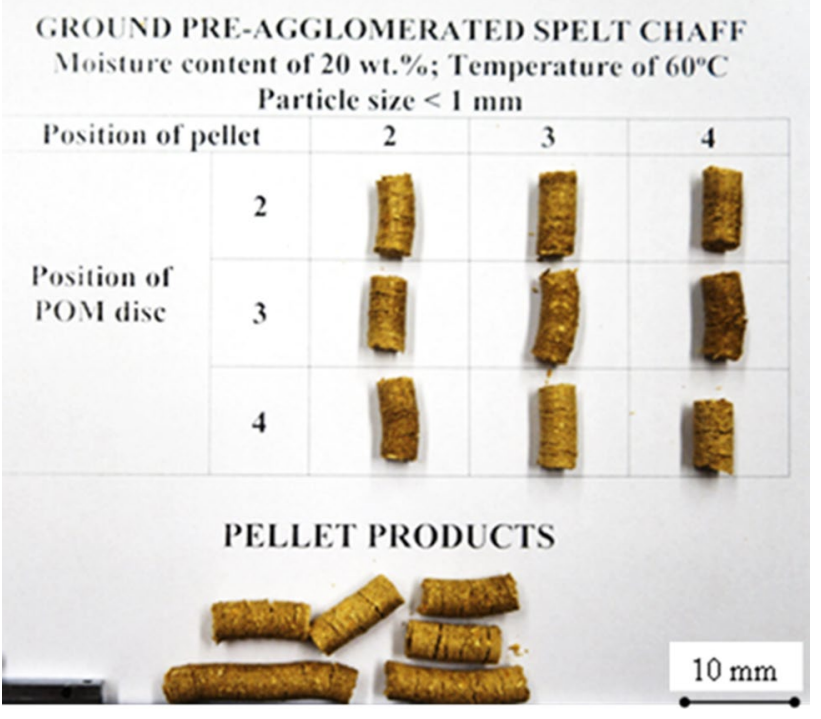

Fig. 12 Pellets produced by the single pelletiser unit

Measured radial back pressure values decrease along the direction of the applied force ( $\mathrm{x}$ axis) in the active part (Table 3). At $20 \mathrm{wt} \%$ moisture content and $60{ }^{\circ} \mathrm{C}$ temperature, pressures are in the 9-23.7 bar range (Fig. 14). At $20 \mathrm{wt} \%$ moisture content and $20{ }^{\circ} \mathrm{C}$ temperature, this range is from 8.4 to 21.1 bar (Fig. 13). Regarding the density, it is observed that increasing radial back pressure results in higher density at the same position of the BPMD load cell.

In each pelletising segment, the measured body density and radial pressure values are average measured values characterising the total $13.75 \mathrm{~mm}$ height segment. Therefore, in Figs. 13 and 14 bars represent these average values. However, a point can be plotted in the centre point of each segment and in this way functions can be fitted to the measured points. Dotted lines represent a density or radial pressure curve as a function of $\mathrm{x}$ (position in the channel). The aim of this early stage curve fitting is only the determination of the initial body density and initial radial pressure at the $\mathrm{x}=0 \mathrm{~mm}$ point. The initial body density values are $\rho_{\mathrm{o}}\left(20^{\circ} \mathrm{C}\right)=1100 \mathrm{~kg} / \mathrm{m}^{3}$ and $\rho_{\mathrm{o}}\left(60^{\circ} \mathrm{C}\right)=1100 \mathrm{~kg} / \mathrm{m}^{3}$. The initial radial pressure values are $\mathrm{p}_{\mathrm{Ro}}\left(20^{\circ} \mathrm{C}\right)=34 \mathrm{bar}$ and $\mathrm{p}_{\mathrm{Ro}}\left(60^{\circ} \mathrm{C}\right)=37$ bar. Curves shown in Figs. 13 and 14 can be transformed into dimensionless forms by the
Table 1 Relationship between number of layers and radial back pressure

\begin{tabular}{llllllll}
\hline Radial back pressure, $\mathrm{p}_{\mathrm{R}}$ (bar) & \multicolumn{7}{l}{} \\
\hline Temperature $\left({ }^{\circ} \mathrm{C}\right)$ & $20{ }^{\circ} \mathrm{C}$ & & & & & \\
\hline Number of layers $(\mathrm{C})$ & & 10 & 20 & $\mathrm{p}_{\mathrm{R}}\left(\mathrm{n}_{\max }\right)$ & 10 & 20 & $\mathrm{p}_{\mathrm{R}}\left(\mathrm{n}_{\max }\right)$ \\
Position of BPMD & 2 & 3.0 & 9.8 & $21.1(33)$ & 5.9 & 10.3 & $23.7(34)$ \\
& 3 & 2.7 & 9.1 & $9.9(29)$ & 3.4 & 9.8 & $14.9(31)$ \\
& 4 & 2.4 & 5.5 & $8.4(24)$ & 2.4 & 5.2 & $9.6(29)$ \\
\hline
\end{tabular}


Table 2 Body density distribution of measured pellet segments

\begin{tabular}{|c|c|c|c|c|c|c|c|}
\hline \multicolumn{8}{|c|}{ Density of pellet segments, $\rho\left(\mathrm{kg} / \mathrm{m}^{3}\right)$} \\
\hline \multicolumn{2}{|l|}{ Temperature } & \multicolumn{3}{|l|}{$20^{\circ} \mathrm{C}$} & \multicolumn{3}{|l|}{$60^{\circ} \mathrm{C}$} \\
\hline \multicolumn{2}{|c|}{ Number of pellet segment } & 2 & 3 & 4 & 2 & 3 & 4 \\
\hline \multirow[t]{3}{*}{ Position of BPMD } & 2 & 1080 & 971 & 901 & 1093 & 1021 & 902 \\
\hline & 3 & 1056 & 959 & 907 & 1103 & 987 & 935 \\
\hline & 4 & 1054 & 856 & 631 & 1095 & 886 & 773 \\
\hline
\end{tabular}

Table 3 Measured pellet segment density and radial back pressure values

\begin{tabular}{|c|c|c|c|c|}
\hline \multirow{2}{*}{$\begin{array}{l}\text { Temperature }\left({ }^{\circ} \mathrm{C}\right) \\
\text { Density/backup pressure }\end{array}$} & \multicolumn{2}{|l|}{$20^{\circ} \mathrm{C}$} & \multicolumn{2}{|l|}{$60{ }^{\circ} \mathrm{C}$} \\
\hline & $\rho\left(\mathrm{kg} / \mathrm{m}^{3}\right)$ & $\mathrm{p}_{\mathrm{R}}(\mathrm{bar})$ & $\rho\left(\mathrm{kg} / \mathrm{m}^{3}\right)$ & $\mathrm{p}_{\mathrm{R}}(\mathrm{bar})$ \\
\hline \multicolumn{5}{|l|}{ Position of BPMD } \\
\hline 2 & 1080 & 21.1 & 1093 & 23.7 \\
\hline 3 & 959 & 9.9 & 987 & 14.9 \\
\hline 4 & 631 & 8.4 & 773 & 9.6 \\
\hline
\end{tabular}
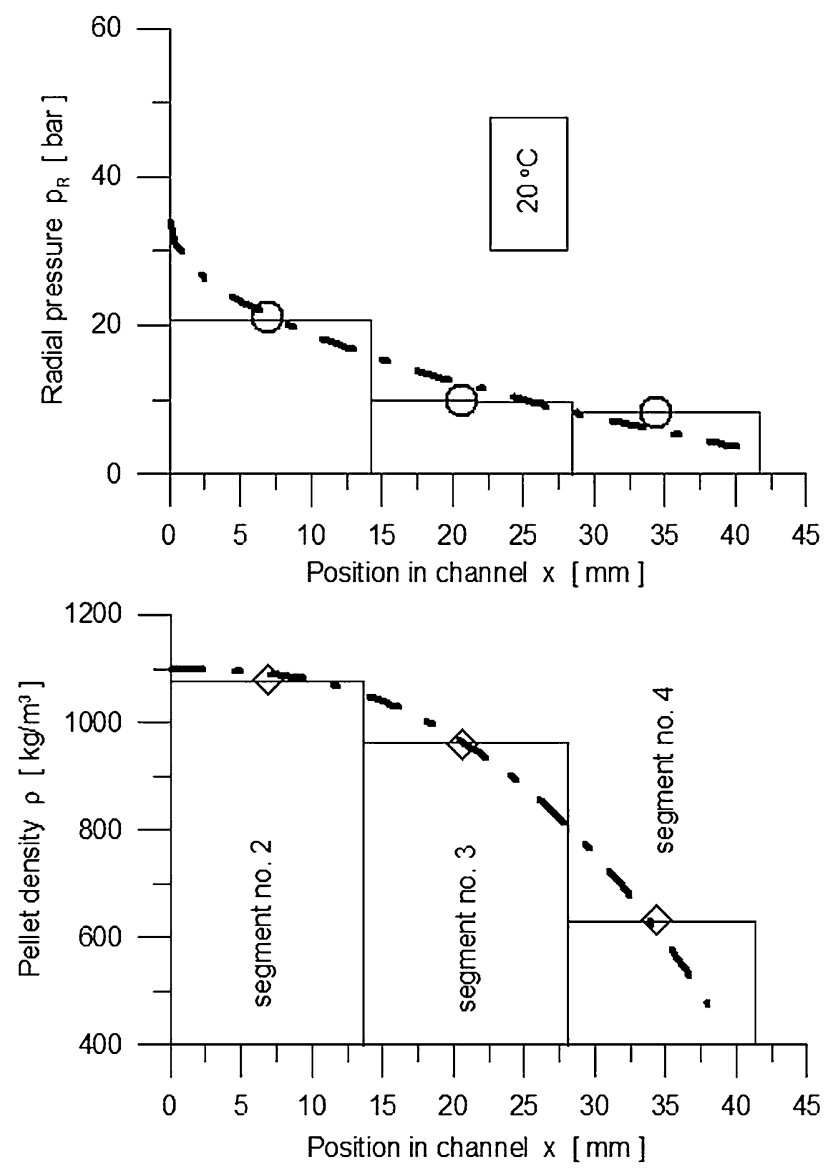

Fig. 13 Pellet segment density (bottom) and radial back pressure distribution (top) along $\mathrm{x}$ at $20^{\circ} \mathrm{C}$
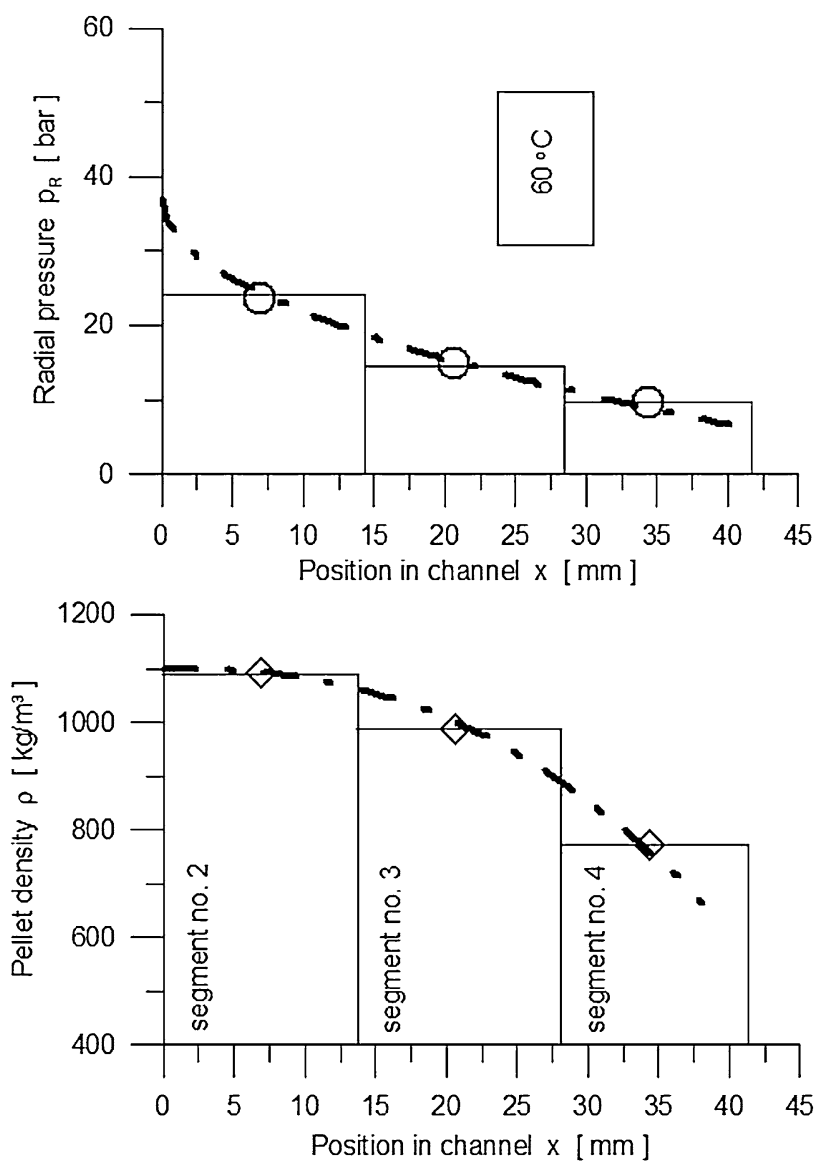

Fig. 14 Pellet segment density (bottom) and radial back pressure distribution (top) along $\mathrm{x}$ at $60{ }^{\circ} \mathrm{C}$

introduction of the following relative parameters: $\rho / \rho_{\mathrm{o}} ; \mathrm{p}_{\mathrm{R}} /$ $\mathrm{p}_{\mathrm{Ro}}$ and $\mathrm{x} / \mathrm{x}_{\mathrm{C}}$. The relative density $\left(\rho / \rho_{\mathrm{o}}\right)$ and relative radial pressure $\left(\mathrm{p}_{\mathrm{R}} / \mathrm{p}_{\mathrm{Ro}}\right)$ are 1 at the initial point $(\mathrm{x}=0 \mathrm{~mm})$. The active length of the pelletising channel is $\mathrm{x}_{\mathrm{C}}=41.25 \mathrm{~mm}$, therefore the relative position $\left(\mathrm{x}_{\mathrm{x}} \mathrm{x}\right)$ is 0 at the starting point and it is 1 at the endpoint of the channel. Figure 15 shows the measured relative density -relative position points.

In this form, as Fig. 15 shows, the following dimensionless function can be well fitted: 


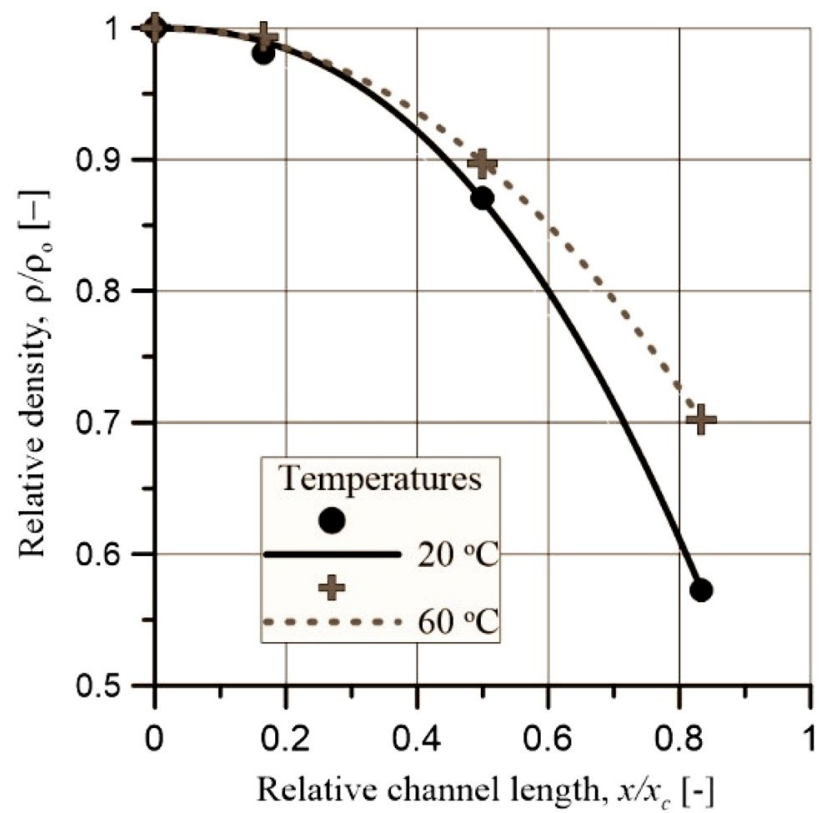

Fig. 15 Relative density $\left(\rho / \rho_{\mathrm{o}}\right)$ as a function of the relative position $\left(\mathrm{x} / \mathrm{x}_{\mathrm{C}}\right)$

Table 4 Parameters curve-fitted to the density results

Tempera- Initial density a (constant), - $\mathrm{b}$ (exponent), $-\quad \mathrm{R}^{2},-$ ture, ${ }^{\circ} \mathrm{C} \quad\left(\rho_{\mathrm{o}}\right), \mathrm{kg} / \mathrm{m}^{3}$

\begin{tabular}{lllll}
\hline 20 & 1100 & 0.65 & 2.32 & 0.9994 \\
60 & 1100 & 0.44 & 2.1 & 0.9997 \\
\hline
\end{tabular}

$\frac{\rho}{\rho_{o}}=1-a \cdot\left(\frac{x}{x_{C}}\right)^{b}$

The parameters of curve fitting are summarised in Table 4.

The high coefficient of determination $\left(\mathrm{R}^{2}\right)$ values indicate that the introduced function (Eq. 3) fits well with the measured data. Figure 16 shows the measured relative radial pressure-relative position points.

As Fig. 16 shows, in this form the following dimensionless function can be well fitted:

$\frac{p_{R}}{p_{R o}}=1-c \cdot\left(\frac{x}{x_{C}}\right)^{d}$

The parameters of curve fitting are summarised in Table 5.

The high coefficient of determination $\left(\mathrm{R}^{2}\right)$ values indicate that the introduced function (Eq. 4) fits the measured data well. However, there is a slightly lower $\mathrm{R}^{2}$ value for the $20{ }^{\circ} \mathrm{C}$ test results, because in the last pelletiser segment the measured radial pressure is relatively high. The same type of

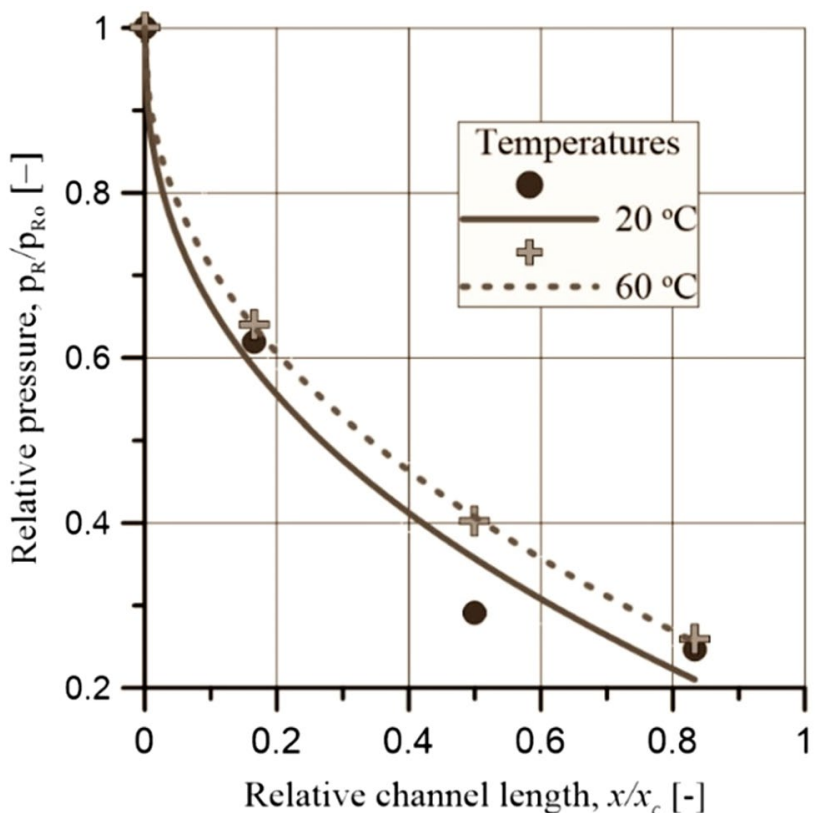

Fig. 16 Relative radial pressure $\left(\mathrm{p}_{\mathrm{R}} / \mathrm{p}_{\mathrm{Ro}}\right)$ as a function of the relative position $\left(\mathrm{x} / \mathrm{x}_{\mathrm{C}}\right)$

Table 5 Parameters curve-fitted to the radial pressure results

\begin{tabular}{lllll}
\hline $\begin{array}{l}\text { Tem- } \\
\text { perature, } \\
{ }^{\circ} \mathrm{C}\end{array}$ & $\begin{array}{l}\text { Initial radial } \\
\text { pressure }\left(\mathrm{p}_{\mathrm{Ro}}\right), \\
\text { bar }\end{array}$ & $\mathrm{c}$ (constant), & $\mathrm{d}$ (exponent), & $\mathrm{R}^{2},-$ \\
\hline 20 & 34 & 0.85 & 0.4 & 0.9813 \\
60 & 37 & 0.81 & 0.45 & 0.9998 \\
\hline
\end{tabular}

power law function (Eqs. 3 and 4) can be applied to the body density and the radial pressure, but note that the exponent for the density is $b>1$ and for the radial pressure it is $d<1$. The measured exponents indicate different density and radial pressure tendencies in the pelletising channel. Equation 2, developed by Holm et al. (2006), estimates the necessary longitudinal pressure for a continuous pelletising operation for producing pellets in a given length channel. The industrial pelletising machines should be run according to this operational condition, namely the pellets should not stop in the channels. The movement in a channel is actually semicontinuous according to the sequential nature of feed of ring die and flat die pelletisers. The operators should avoid the permanent stop of the raw material in the channels. In this paper, a novel method and equipment is reported where the pellet movement in the channel was stopped at a given pre-set pelletising pressure and in this state, the density and radial pressure distributions were measured. It is obvious now that Eq. 2 cannot be used to describe tests under these different conditions. However, experimental Eqs. 3 and 4 display a very good fit with measured data. 
According to the literature review, no test device for pressure distribution measurement inside a press channel exists, typically the pelletising force on the die is measured. Therefore, the comparison of these novel results with literature data is not possible.

\section{Conclusion}

A single pelletising unit and a novel sensor, namely the back pressure measurement disc (BPMD), were developed and calibrated. Using this instrument, the upper pressure limit of a ring die or flat die pelletising machine can be determined. For a given pre-set pressure, the number of sequentially loaded biomass portions can be determined at the point when the movement of the compressed biomass in the press channel stops. This condition should be avoided with industrial machines, therefore it is important to predict such pressures. The developed instruments and test protocols make it possible to measure the body density and radial pressure distribution in the press channel.

According to the measurement results, the material of the press channel wall (steel, POM, BPMD) influenced the density and radial pressure distribution in the channel. The effect of the different wall friction coefficient on the radial pressure seems to be apparent, because wall friction supports the pelletising piston. Experiments however have shown that the wall cannot be treated as fully rigid, because the different Poisson ratios of different wall materials also affected pelletising.

Dimensionless power law relative body density-relative position and relative radial pressure-relative position functions were introduced for the measured data. The very high coefficient of determination $\left(\mathrm{R}^{2}\right)$ values indicate good fit. The same type of power law function (Eqs. 3 and 4) can be applied for the body density and the radial pressure, but the exponent for the density is $b>1$ and for the radial pressure it is $\mathrm{d}<1$. The measured exponents indicate different density and radial pressure tendencies in the pelletising channel.

The developed new load cell, single pelletising unit and test protocol can be used right now to test and model only the upper limit,-when the continuous flow in the channel stops and the piston is backed - of industrial machines operation. That is a challenge for the future to further develop the protocol to carry out tests during continuous pelletising.

Acknowledgements Open access funding provided by Linnaeus University. The authors thank Dr. Ádám Rácz and Viktor Kövesi for manufacturing the single pelletiser unit. Gábor Antal is thanked for his valuable comments and suggestions. The research work of Trinh Van Quyen was supported by a Stipendium Hungaricum Scholarship. The described article was carried out as part of the "Sustainable Raw Material Management Thematic Network-RING 2017",
EFOP-3.6.2-16-2017-00010 project in the framework of the Széchenyi 2020 program. The realisation of these projects is supported by the European Union, co-financed by the European Social Fund.

Open Access This article is licensed under a Creative Commons Attribution 4.0 International License, which permits use, sharing, adaptation, distribution and reproduction in any medium or format, as long as you give appropriate credit to the original author(s) and the source, provide a link to the Creative Commons licence, and indicate if changes were made. The images or other third party material in this article are included in the article's Creative Commons licence, unless indicated otherwise in a credit line to the material. If material is not included in the article's Creative Commons licence and your intended use is not permitted by statutory regulation or exceeds the permitted use, you will need to obtain permission directly from the copyright holder. To view a copy of this licence, visit http://creativecommons.org/licenses/by/4.0/.

\section{References}

Adapa PK, Tabil L, Schoenau GJ (2009) Compaction characteristics of barley, canola, oat and wheat straw. Biosyst Eng 104(3):335-344 Andreiko D, Grochowicz J (2007) Effect of moisture content on compression energy and strength characteristic of lupine briquettes. $\mathrm{J}$ Food Eng 83(1):116-120

Arshadi M, Gref R, Geladi P, Dahlqvist S, Lestander T (2008) The influence of raw material characteristics on the industrial pelletizing process and pellet quality. Fuel Process Technol 89(12):1442-1447

Carone MT, Pantaleo A, Pellerano A (2011) Influence of process parameters and biomass characteristics on the durability of pellets from the pruning residues of Olea europaea L. Biomass Bioenergy 35(1):402-410

Filbakk T, Skjevrak G, Hoibo O, Dibdiakova J, Jirjis R (2011) The influence of storage and drying methods for scots pine raw material on mechanical pellet properties and production parameters. Fuel Process Technol 92(5):871-878

Gercek H (2007) Poisson's ratio values for rocks. Int J Rock Mech Min Sci 44:1-13

Gilbert P, Ryu C, Sharifi V, Swithenbank J (2009) Effect of process parameters on pelletisation of herbaceous crops. Fuel 88(8):1491-1497

Holm JK, Henriksen UB, Hustad JE, Sorensen LH (2006) Toward an understanding of controlling parameters in softwood and hardwood pellets production. Energy Fuels 20(6):2686-2694

Holm JK, Henriksen UB, Wand K, Hustad JE, Posselt D (2007) Experimental verification of novel pellet model using a single pelleter unit. Energy Fuels 21:2446-2449

Holm JK, Stelte W, Posselt D, Ahrenfeldt J, Jenriksen UB (2011) Optimization of a multiparameter model for biomass palletization to investigate temperature dependence and to facilitate fast testing of pelletization behavior. Energy Fuels 25(8):3706-3711

Howatson AM, Lund PG, Todd JD (1991) Engineering tables and data, 2nd edn. Chapman \& Hall, London

Kaliyan N, Morey RV (2009) Densification characteristics of corn stover and switchgrass. Trans ASABE 52(3):907-920

Lisowski A, Pajor M, Świętochowski A et al (2019) Effect of moisture content, temperature, and die thickness on the compaction process and the density and strength of walnut shell pellets. Renew Energy 141:770-781

Mani S, Tabil LG, Sokhansanj S (2006) Effects of compressive force, particle size and moisture content on mechanical properties of biomass pellets from grasses. Biomass Bioenergy 30(7):648-654 
Nielsen NPK, Gardner DJ, Poulsen T, Felby C (2009a) Importance of temperature, moisture content, and species for the conversion process of wood residues into fuel pellets. Wood Fiber Sci 41(4):414-425

Nielsen NPK, Holm JK, Felby C (2009b) Effect of fiber orientation on compression and frictional properties of sawdust particles in fuel pellet production. Energy Fuels 23(6):3211-3216

Nielsen NPK, Gardner DJ, Felby C (2010) Effect of extractives and storage on the Pelletising process of sawdust. Fuel 89(1):94-98

Odogherty MJ, Wheeler JA (1984) Compression of straw to highdensities in closed cylindrical dies. J Agric Eng Res 29(1):61-72

Pöyry (2011) Pellets - becoming a global commodity Perspectives on the global pellet market to 2020. Viewpoint report, Pöyry, Vantaa, Finland

Rhen C, Gref R, Sjostrom M, Wasterlund I (2005) Effects of raw material moisture content, densification pressure and temperature on some properties of Norway spruce pellets. Fuel Process Technol 87(1):11-16

Ryu C, Finney K, Sharifi VN, Swithenbank J (2008) Pelletised fuel production from coal tailings and spent mushroom compost-part I-identification of pelletisation parameters. Fuel Process Technol 89(3):269-275

Serrano C, Monedero E, Lapuerta M, Portero H (2011) Effect of moisture content, particle size and pine addition on quality parameters of barley straw pellets. Fuel Process Technol 92(3):699-706

Smith IE, Probert SD, Stokes RE, Hansford RJ (1977) Briquetting of wheat straw. J Agric Eng Res 22(2):105-111

Stelte W, Holm JK, Sanadi AR, Ahrenfeldt J, Henriksen UB (2011) Fuel pellets from biomass: the importance of the pelletizing pressure and its dependency on the processing conditions. Fuel 90(11):3285-3290
Stelte W, Clemons C, Holm JK, Sanadi RA, Shang L, Ahrenfeldt J, Henriksen UB (2012) Fuel pellets from wheat straw: the effect of lignin glass transition and surface waxes on pelletizing properties. Bioenerg Res 5(2):450-458

Strauss W (2017) Overview of global pellet markets. E2tech conference: the new forest economy-Biobased power, products, \& fuels. March 27, 2017. Hallowell, Maine, USA. https://e2tech.org/ resources/Pictures/Strauss_FutureMetrics_ForestEconomy_3-2417.pdf

Trinh VQ, Nagy S (2016) Development of single pelletiser unit for modeling flat die pelletiser. In: MultiScience-XXX. microCAD International multidisciplinary scientific conference University of Miskolc, Hungary

Tumuluru SJ, Wright TC, Hess RJ, Kenney LK (2010) A Review on biomass densification technologies for energy application. Idaho National Laboratory Biofuels and Renewable Energy Technologies, Department Energy Systems and Technologies Division, Idaho

Yanming W, Zhongjia C, Xiangyue Y, Guosheng Y (2018) Influence of die temperature and moisture content on the densification of bamboo powder using die heating method. Wood Res 63(4):655-668

Zhu F, Zhang Y, Wang WZ (2017) Study on the thermal expansion coefficient of a thermalization infrared lens' thermal compensation element. In: Patty A, Peijiang Z (eds) Advances in materials science, energy technology and environmental engineering. Taylor \& Francis Group, London

Publisher's Note Springer Nature remains neutral with regard to jurisdictional claims in published maps and institutional affiliations. 